\title{
Granular myringitis: current status of management
}

\author{
Mohan Bansal* \\ Department of E. N. T., GAIMS, Bhuj, Gujarat, India \\ Received: 30 September 2015 \\ Accepted: 02 October 2015 \\ *Correspondence: \\ Dr. Mohan Bansal, \\ E-mail: mohanbansal@yahoo.com \\ Copyright: (c) the author(s), publisher and licensee Medip Academy. This is an open-access article distributed under \\ the terms of the Creative Commons Attribution Non-Commercial License, which permits unrestricted non-commercial \\ use, distribution, and reproduction in any medium, provided the original work is properly cited.
}

\begin{abstract}
The Granular Myringitis (GM) is not uncommon though in medical literature it has been reported among the rarer conditions. The aim of this article is to review the clinical features and management of Granular Myringitis (GM). GM is characterized by granulation tissue on the outer surface of the Tympanic Membrane (TM) with or without the involvement of deep bony External Auditory Canal (EAC). The granulations are either localized or diffuse. The granulations over tympanic membrane continue to grow slowly for years. The ensuing fibrosis in patients with granulations of deep bony meatal wall can result into an atresia of the deep bony EAC. The presenting symptom of GM is an ear discharge which may be foul-smelling. However many patients have a sensation of fullness, irritation, mild pain or itching in the ear. If perforation occurs the underlay perichondrium or temporalis fascia grafting is done. In some of the refractory cases granulations are removed and the raw area is covered with skin. Many patients respond well to meticulous microscopic aural toilet and topical antibiotic and steroid ear drops. If patients do not respond then application of topical caustic agents are employed.
\end{abstract}

Keywords: Granular myringitis, Tympanic membrane, External auditory canal, Granular otitis externa, Otitis

\section{INTRODUCTION}

Granular Myringitis (GM) is a chronic inflammation that is confined to the squamous layer of the Tympanic Membrane (TM). It was considered among the rarer diseases of the ear. ${ }^{1}$ Even major institutes report fewer than 100 patients over several years. But in one study, its incidence has been found to be a quarter of that of cholesteatoma patients. $^{2}$ GM can occur even after tympanoplasty surgery. As a postoperative complication of TM grafting, an incidence of up to 5 percent has been reported. The higher incidence ( 8 percent) is seen with the use of tympanic homografts. ${ }^{3}$ The incidence of granular myringitis is not related to sex, age, particular systemic diseases or seasons. ${ }^{2} \mathrm{GM}$ is characterized by granulation tissue on the outer surface of the TM with or without the involvement of deep bony External Auditory Canal (EAC). ${ }^{4}$ GM has been reported in the medical literature under various names such as myringitis granulose, ${ }^{5}$ acute granulomatous myringitis ${ }^{6}$ and chronic myringitis. ${ }^{7}$

It has been suggested that a nonspecific injury involving the lamina propria of the TM suppresses epithelialization that leads to the development of granulations. A bacterial and fungal infection is implicated in all reports. ${ }^{8,9}$ Though not confirmed, many causative factors have been suggested such as high-ambient temperature, swimming, lack of hygiene, local irritants and foreign bodies. ${ }^{10}$ Histopathology shows edematous granulation tissue with capillaries and diffuse infiltration of chronic inflammatory cells. Majority of the granulation tissue has no covering epithelium. ${ }^{11}$ Over a period of weeks or months proliferating granulation tissue may creep laterally along the deep bony portion of the External Auditory Canal (EAC). Over a period of 2 or 3 decades squamous epithelium may grow over the surface of the granulation to give the appearance of a stenotic bony 
EAC. The several millimeters of thick fibrous tissue may lie between the normal fibrous layer of the TM and the external cuticle layer. Early treatment can reverse this process. ${ }^{12}$ Many cases, however, prove intractable. These patients need surgical excision of necrotic region.

\section{METHODS}

The data in this article are supported by a Medline search using the key words otitis externa, external otitis, granular myringitis, granular otitis externa and myringitis. These were augmented by references from these articles. No limits were applied to year of study; however I did exclude publications that were not in English. Relevant articles not found in the Medline were sought by a hand search review of reference books. Data were extracted into a database developed for this systematic review. The data extracted included author, year of publication, evidence level of study, and recommendations made or disputed.

\section{DATA ANALYSIS}

GM is of unknown etiology and runs a painless course. Some of the patients can be asymptomatic and granulations are seen as an incidental finding on ear microexamination. The presenting symptom is an ear discharge which may be foul-smelling. Many patients have a sensation of fullness, irritation, mild pain or itching in the ear. Some patients have slightly impaired hearing ${ }^{13}$. Many patients remain asymptomatic and spontaneous healing occurs in symptomatic patients. GM usually has a chronic course and granulations continue to grow slowly for years. The inflammation in the epithelial layer and lamina propria of the TM may be replaced with proliferating granulation tissue and fibrosis and can result into an atresia of the deep bony EAC. ${ }^{1}$ The most common symptoms are itching, ear discharge and hearing loss. The tinnitus and severe pain are uncommon symptoms. GM is only occasionally accompanied by fleeting lancinating pain in the ear. The bony external ear canal contains purulent secretions and granulations. ${ }^{14}$ The aural toilet will reveal whether the granulations are localized or diffuse. In cases of primary idiopathic GM, perforation of $\mathrm{TM}$ is not present, hearing is not impaired and there is normal movement of the tympanic membrane on pneumatic otoscopy. ${ }^{15}$

Granulations are usually covered with moderate amount of purulent secretions that sometimes crust. The granulations usually have a sessile base and occur on the deep bony external ear canal and superficial surface of tympanic membrane. ${ }^{13}$ They may be pedunculated. The localized form, which is most common, involves small areas of TM. The most common site of granulations is posterosuperior quadrant of TM. It may affect the deep bony EAC. One or more polyps can be seen in some cases. In diffuse form, a slightly raised carpet of granulations covers the TM. ${ }^{14}$

\section{DISCUSSION}

The GM must be differentiated from Chronic Suppurative Otitis Media (CSOM) and diffuse external otitis. Patients with diffuse external otitis will have an inflammatory reaction in the lateral part of EAC. Generalized otitis externa, either acute or chronic can change appearance of TM. The outer epithelial layer of TM is a continuation of the squamous epithelium of EAC. In patients with chronic otitis externa, the TM may look dull red or thickened or leathery. The TM becomes less sensitive than normal. ${ }^{1}$ The CSOM patients will have conductive hearing loss and TM perforation. A normal Computed Tomography (CT) scan will also exclude chronic otitis media. Granulations tissue of TM usually indicates that TM has been perforated and granulations are arising from the middle ear mucosa and protruding through the perforated TM. Careful ear-microscopy may reveal a pinhole perforation in patients with granular myringitis. These patients are generally not considered as cases of primary granular myringitis. ${ }^{12}$ In cases of suspicion of middle ear and mastoid involvement, High Resolution Computed Tomography (HRCT) of temporal bone will exclude chronic otitis media. In refractory patients when the granulations do not resolve with treatment, biopsy will exclude carcinoma. Tympanometry will rule out the middle ear pathology. Pure-tone audiometry will exclude conductive hearing loss due to otitis media. Culture for bacteria and fungi is indicated when conservative treatment with antibiotic-steroid ear drops fails. The commonly cultured microorganisms are Pseudomonas aeruginosa, Proteus species, Staphylococcus aureus, and Candida albicans. ${ }^{8,9}$

Various antibiotics have been used, but none is evaluated with in a controlled way. If needed the antibiotic and/or antifungal agents may be based on the results of the culture and sensitivity reports. ${ }^{16}$ Many patients respond well to meticulous microscopic aural toilet and topical antibiotic and steroid ear drops. The treatment is continued for at least two weeks. If patients do not respond then application of topical caustic agents (such as chromic acid, formalin, or silver nitrate) should be employed. ${ }^{13,17}$ The topical application of formalin $(0.5 \%)$ or trichloroacetic acid once a week has shown good results. Strong caustic agents are not used as they can damage the fibrous layer of TM. In some of the refractory cases where conservative treatment fails, earmicrosurgery is done. Surgical treatment consists in removal of the granulations with small forceps and ear packing with Gelfoam soaked in an antibiotic-cortisone ear drops to prevent recurrence. In cases of stenotic bony EAC, the mass is surgically excised skin flaps or grafts are fashioned to re-epithelialize the EAC and TM. In cases of preauricular pain and tenderness one must rule out fistulous tracts with necrosis of underlying cartilage and bone. The base may be cauterized with silver nitrate on a very fine probe, and antibiotic and steroid eardrops instilled. The search for underlying causes such as diabetes, particularly in elderly patients is important. 
Laser evaporization of granulations has also been employed. ${ }^{18}$ The treatment is usually successful. The granulations are removed and the raw area is covered with skin or underlay perichondrium. If perforation occurs the temporalis fascia grafting is carried out. Surgical treatment is considered in refractory cases and consists of removal of the granulations. ${ }^{19}$

\section{CONCLUSION}

The chronic inflammation confined to the squamous layer of the tympanic membrane is not rare. GM is of unknown etiology and runs a painless course. A nonspecific injury involving the lamina propria of the TM suppresses epithelialization and leads to the development of granulations. The presenting symptom is an ear discharge which may be foul-smelling. Other symptoms include sensation of fullness, irritation, mild pain or itching in the ear. The inflammation of epithelium and lamina propria of the TM is replaced with proliferating granulation tissue and fibrosis. GM should be differentiated from Chronic Suppurative Otitis Media (CSOM) and diffuse external otitis. Usually patients respond well to meticulous microscopic aural toilet and topical antibiotic and steroid ear drops. If patients do not respond then application of topical caustic agents are employed.

Funding: No funding sources

Conflict of interest: None declared

Ethical approval: Not required

\section{REFERENCES}

1. Pulec JL, Kinney SE. Diseases of the tympanic membrane. In: Paparella MM, Shumrick DA, eds. Otolaryngology. 2nd ed. Philadelphia PPA, USA: WB Saunders Company; 1973: 55-74.

2. Wolf M, Primov-Fever A, Barshack I, PolackCharcon S, Kronenberg J. Granular myringitis: Incidence and clinical characteristics. Otol Neurotol. 2006;27(8):1094-7.

3. Puls T. Myringoplasty: is molded collagen xenograft a valid alternative for fresh temporalis fascia? Acta Otorhinolaryngol Belg. 1996;50(2):111-4.

4. Stoney P, Kwok P, Hawke M. Granular myringitis: a review. J Otolaryngol. 1992;21(2):129-35.

5. Boedts D. Myringitis granulosa. Acta Otorhinolaryngol Belg. 1995;49(2):187-9.

6. Hoshino $\mathrm{T}$, Ueda Y, Mukohdaka H, Mizuta K. Acute granulomatous myringitis. J Laryngol Otol. 1998;112(2):150-3.
7. Blevins NH, Karmody CS. Chronic myringitis: prevalence, presentation, and natural history. Otol Neurotol. 2001;22(1):3-10.

8. Hwang JH, Chu CK, Liu TC. Changes in bacteriology of discharging ears. J Laryngol Otol. 2002;116(9):686-9.

9. Hwang JH, Tsai HY, Liu TC. Community-acquired methicillin-resistant Staphylococcus aureus infections in discharging ears. Acta Otolaryngol. 2002;122(8):827-30.

10. Kunachak S. Intractable granular myringitis: possible etiology and management. J Otolaryngol. 1992;21:297-8.

11. McLaurin JW. Trauma and infections of the external ear. In: Paparella MM, Shumrick DA, eds. Otolaryngology. 2nd ed. Philadelphia PPA, USA: WB Saunders Company; 1973: 24-32.

12. DeWeese DD, Saunders WH, Schuller DE, Schleuning AJ. Infection and inflammation of the ear. In: DeWeese DD, Saunders WH, Schuller DE, Schleuning AJ, eds. Otolaryngology - Head and Neck Surgery. 7th ed. St Louis USA: The C.V. Mosby Company; 1988: 395-425.

13. Kim YH. Clinical characteristics of granular myringitis treated with castellani solution. Eur Arch Otorhinolaryngol. 2011;268(8):1139-46.

14. Makino K, Amatsu M, Kinishi M, Mohri M. The clinical features and pathogenesis of myringitis granulosa. Arch Otorhinoloryngol. 1988;245:224-9.

15. Neilson LJ, Hussain SS. Management of granular myringitis: a systematic review. J Laryngol Otol. 2008;122(1):3-10.

16. Jinnouchi O, Kuwahara T, Ishida S, Okano Y, Kasei $\mathrm{Y}$, Kunitomo $\mathrm{K}$, et al. Anti-microbial and therapeutic effects of modified Burow's solution on refractory otorrhea. Auris Nasus Larynx. 2012;39(4):374-7.

17. Jung HH, Cho SD, Yoo CK, Lim HH, Chae SW. Vinegar treatment in the management of granular myringitis. J Laryngol Otol. 2002;116(3):176-80.

18. Fechner FP, Cunningham MJ, Eavey RD. Laser therapy for refractory myringitis in children. Otolaryngol Head Neck Surg. 2002;127(3):163-8.

19. Zhang Z, Liu X, Chen S, Zheng Y. Combined tympanic epithelial layer avulsion and overlay myringoplasty for diffuse granular myringitis. J Laryngol Otol. 2010;124(8):842-5.

Cite this article as: Bansal M. Granular myringitis: current status of management. Int J Otorhinolaryngol Head Neck Surg 2015;1:55-7. 